\title{
Dermatoglyphic analysis of hypothenar traits in twins
}

\begin{abstract}
There are single dermatoglyphic investigations devoted to hypothenar traits in twins. In the present concise review, some aspects of this specific research topic are described. Attention is paid to the geographical distribution of qualitative palmar dermatoglyphic traits in several countries in Europe and Asia. Hypothenar traits in monozygotic and dizygotic twins under normal conditions as well as in a variety of common diseases are described. The importance of qualitative palmar dermatoglyphic investigations in patients with malignant diseases is outlined.
\end{abstract}

Keywords: palmar dermatoglyphic traits, hypothenar, monozygotic twins, dizygotic twins, oncological diseases
Volume 6 Issue 3 - 2019

\section{Yaneva Galina,' Gergana Ingilizova, ${ }^{2}$ Dobri Ivanov'}

'Department of Biology, Medical University of Varna, Bulgaria ${ }^{2}$ Vita Multidisciplinary Hospital for Active Treatment, Bulgaria

Correspondence: Yaneva Galina, Department of Biology, Faculty of Pharmacy, Medical University of Varna,Varna 9003, 55 Marin Drinov Street, Bulgaria, Email galina.yanevaa@gmail.com

Received: June 12, 2019 | Published: June 28, 2019

\section{Introduction}

Dermatoglyphs are polygenetically determined epidermal ridge configurations on the fingers, palms and soles in man. ${ }^{1}$ The 'twin' method is successfully used when comparing the degree of individual genetic predisposition to disease with the influences of environmental factors on human health by using qualitative and quantitative indicators. ${ }^{2}$ At presence, there are relatively few dermatoglyphic studies of hypothenar in twins in the literature available.

\section{Geographical distributions of palmar dermatoglyphic traits}

The distribution of 12 dermatoglyphic variables in 22 populations of Romania is analyzed by means of geographical and historical relationships. ${ }^{3}$ There is hypothenar radial arch in $2.07 \%$ of the males and $2.82 \%$ of females among 2,130 Bulgarians. ${ }^{4}$ Persons bearing the pattern on the right hand display the highest frequency, followed by those bearing it bilaterally and those bearing it on the left hand. In 264 right-, 246 mixed- and 360 left-handers in Bulgaria, the hypothenar radial arch, along with its considerably higher frequency in females than in males and on the right palm than on the left one, as well as its rarity combined with a very high symmetry displays an interesting peculiarity. ${ }^{5}$

The within and between pair mean squares and means are estimated for dermatoglyphie patterns on palms and compared between samples of 110 monozygotic and 111 dizygotic twins of Polish origin. ${ }^{6}$ The highest values of genetic parameters have been obtained for the hypothenar loop. The study of sexual dimorphism in palmar dermatoglyphic traits of 894 unrelated, clinically healthy individuals (480 females and 414 males) aged 18-50 years from NorthWest Bulgaria demonstrates that ulnar loops are the most frequent pattern of hypothenar on both hands in both sexes. ${ }^{7}$ In females, they are present in $15.6 \%$ on the left hand and in $12.5 \%$ on the right hand. There are greater frequencies of radial loops (17.4\% in the left hand) and ulnar ones (23.2\% in the left hand and $15.9 \%$ in the right hand) in males than in females. In both sexes, the frequency of patterns in thenar and especially in thenar/I interdigital space is low than that in hypothenar area. In female hypothenar, the frequencies of traces of patterns are $11.9 \%$ in the right hand and $6.9 \%$ in the left hand while in male hypothenar, the corresponding figures are $2.9 \%$ and $1.4 \%$ only. In terms of thenar/I interdigital space, the frequencies of traces of patterns in females are $16.3 \%$ and $21.9 \%$ while those in males are $26.1 \%$ and $44.9 \%$, respectively.

The results from a descriptive analysis of palmar dermatoglyphic traits (pattern frequencies in thenar and hypothenar) of 341 individuals, 141 males and 200 females from Delta de l'Ebre, Catalonia, Spain, demonstrate the highest frequencies of the hypothenar area in both sexes in comparison to other Spanish populations. ${ }^{8}$ The true hypothenar patterns as a component of dermatoglyphic traits are analyzed in 386 individuals, 182 males and 204 females aged between 10 and 18 years from the Central Rhodopes in South Bulgaria. ${ }^{9}$ The geographic variation patterns of six dermatoglyphic traits from 144 samples in Eurasia are described..$^{10}$ The distinct and significant patterns of variation consist in a general north-west to south-east trend concerning the frequency of hypothenar patterns. These results are compatible with a diffusion process between Europe and the peoples of Northern Asia and, possibly, with a radiation of populations from the Middle East. The left and right palms of 499 individuals are classified for Level 1 pattern frequency in the thenar and hypothenar areas to establish a basic system for classifying palmprint patterns. ${ }^{11}$ There are statistically significant differences in the frequency of patterns between right and left palms in the thenar areas $(p<0.001)$ only.

\section{Hypothenar traits in monozygotic and dizygotic twins}

The analysis of the role of genetic factors in the determination of palmar dermatoglyphic patterns in a series of 49 monozygotic and 51 dizygotic twins shows that the genetic effect in the distribution of patterns presents with intermediate values in hypothenar and thenar patterns. ${ }^{12}$ The qualitative examination of the hypothenar traits of both hands from 69 pairs of same-sex twins (32 monozygotic and 37 dizygotic) in the population of Kosovo demonstrates that the heritability patterns sharply distinguish highly heritable dermatoglyphic traits (patterns on the thenar) and the traits with weak genetic component (patterns on the hypothenar). ${ }^{1}$ The noxious environmental factors possibly causing diseases later in life would leave traces on the dermatoglyphs, which could be recognized as the increased dissimilarity of the twins and other relatives in the 
hypothenar. Qualitative analysis of prints concerning the frequency of the patterns on palms such as thenar, I, II, III, and IV interdigital fields and hypothenar reveals significant differences between 800 inhabitants of Dukagjin valley in Kosovo, 400 Albanians and 400 Turks as a proof of substantial reproductive isolation between these two ethnic sub-populations. ${ }^{13}$

Some hypothenar radial loops, ulnar arches, and ulnar loops can be a manifestation of the gene(s) producing the hypothenar whorl. ${ }^{14}$ The analysis of the family pedigree material reveals that matings between two individuals with bilateral radial loops or two individuals with bilateral ulnar arches produce a very high incidence of the parental patterns in the offspring. The relationship between the hypothenar radial loop and the hypothenar whorl as well as the relationship between the other patterns, combined with the somewhat inbred nature of the study population, makes it impossible to determine the mode of inheritance of the hypothenar whorl. It is suggested that the hypothenar whorl is a genetically determined pattern that is probably inherited with reduced penetrance.

The qualitative study of hypothenar traits of 21 pairs of monozygotic and 22 pairs of dizygotic twins from Bulgaria shows that radial loops of the right hand are most common in dizygotic twins (in 16.66\%) and monozygotic ones (in 11.36\%) while ulnar arches are most frequent in the left hand in dizygotic twins (in 33.33\%) and in the right hand of monozygotic ones (in $25 \%$ ). ${ }^{15}$

\section{Hypothenar patterns in human disease}

Qualitative dermatoglyphics comprising of hypothenar pattern and palmar crease are studied in 26 female and 11 male rheumatoid arthritis patients and matched controls. ${ }^{16}$ In male patients, loops are decreased while partial Simian crease is significantly increased. The dermatoglyphic features in 31 female patients who are cytogenetically confirmed as 46, $\mathrm{XY}$ in terms of palmar traits such as Simian crease and hypothenar patterns do not differ statistically significantly from those in 30 male and 30 female control subjects in India in contrast to different finger pattern frequency. ${ }^{17}$

The incidence of hypothenar patterns is evaluated in a dermatoglyphic study of 392 hands of patients with congenital hand anomalies in Japan. ${ }^{18}$ The results deviate from the normal range in cases of ectrodactyly and syndactyly and are within the normal range in patients with polydactyly. The dermatoglyphic traits associated with each type of hand anomaly are characteristic and discriminative. In 42 inpatients meeting the DSM-IV criteria for schizophrenia with early age at disease onset, there is a higher frequency of ulnar loop pattern in the hypothenar area than in 36 normal controls. ${ }^{19}$ Dermatoglyphic studies of 109 physically and mentally handicapped patients, 58 males and 51 females, show significant differences from the general population in terms of the hypothenar patterns. ${ }^{20}$ The association between hypothenar palmar dermatoglyphic features and malocclusion of three different classes in 237 Indian children aged 12-16 years is investigated. ${ }^{21}$ The frequency of ulnar loops prevails considerably in the children with malocclusion - $57.68 \%$ in class I, $55.71 \%$ in class II, and $56.67 \%$ in class III.

\section{Qualitative palmar dermatoglyphics in oncology}

Palmar dermatoglyphics is simple, inexpensive, anatomical and non-invasive method and can be used as a reliable indicator for screening of high-risk breast cancer population. ${ }^{22}$ Heritability provides insight into individual differences in breast cancer predisposition, framing results from genome-wide association studies and missing heritability. Estimates of the shared risk of breast cancer between monozygotic twins with identical genomes represent a upper limit of the potential for genotyping and whole-genome sequencing to classify individuals' risk. ${ }^{23}$ There are several dermatoglyphic studies in patients with malignant diseases demonstrating a correlation of certain dermatoglyphic properties with this pathology. ${ }^{24}$ In a casecontrol, cross sectional study of 60 non-functional pituitary tumour patients ( 30 males at an average age of 42 years and 30 females at an average age of 48 years) and 66 functional pituitary tumour patients (20 males and 46 females at an average age 42 years) as well as of 200 male and 200 female phenotypically healthy individuals without any malignant disease from the Zagreb region, there are statistically significant differences in the hypothenar between the functional tumour and non-functional tumour patients $\left(\chi^{2}=6.871 ; \mathrm{p}=0.009\right)$ or control subjects $\left(\chi^{2}=6.096 ; p=0.014\right)$ in males only. ${ }^{25}$

The dermatoglyphic analysis of 31 children with acute myeloblastic leukaemia and the first-degree relatives of 25 of them proves a genetically determined factor carrying a high risk of disease development. ${ }^{26} \mathrm{~A}$ member of each of five different families of the 25 studied ones bears a rare hypothenar pattern when compared with none in 75 control families. Within a case-control study of 168 ovarian cancer patients and 200 healthy females, the correlation between the occurrence of certain qualitative dermatoglyphic traits and the susceptibility to ovarian cancer is assessed in the University Department of Gynecologic Oncology in Zagreb, Croatia. ${ }^{27}$ There is a statistically significant difference between both groups concerning the palmar patterns in left hand hypothenar $(24 \%$ versus $34 \%$; $<<0.01)$.

Palmar dermatoglyphic traits are qualitatively and quantitatively evaluated in 30 patients with oral leukoplakia, 30 patients with oral squamous cell carcinoma and 30 healthy controls in India. ${ }^{28}$ In the right hand, the frequencies of hypothenar patterns are $80 \%$ in oral leukoplakia patients and controls each and $76.67 \%$ in oral squamous cell carcinoma patients while in the left hand, they are $90 \%, 83.30 \%$ and $73.30 \%$, respectively $\left(\chi^{2}=1.986 ; \mathrm{p}=0.370\right)$. In the right hand, the frequencies of thenar/I interdigital field patterns are $86.67 \%$ in oral leukoplakia patients, $90 \%$ in oral squamous cell carcinoma ones and $83.30 \%$ in controls while in the left hand, they are $76.67 \%, 80 \%$ and $73.30 \%$, respectively $\left(\chi^{2}=0.891 ; \mathrm{p}=0.640\right)$. There are statistically significant differences between 30 oral leukoplakia patients and 30 tobacco using patients without this lesion concerning the hypothenar patterns $(p<0.001) .{ }^{29}$ These dermatoglyphic traits predominate among the patients when compared to the control subjects. The results from a prospective comparative dermatoglyphic study of 10 smokeless tobacco users with oral submucous fibrosis, 10 smokeless tobacco users with oral squamous cell carcinoma, 10 smokeless tobacco users without these diseases, and 10 subjects without smokeless tobacco habit (controls) demonstrate a statistically significant difference in terms of the qualitative and quantitative hypothenar patterns between the patients with these two pathologies $(\mathrm{p}<0.001) .{ }^{30}$ The hypothenar pattern is absent in the patients without these diseases and in the controls. It is present in $55 \%$ of patients with oral submucous fibrosis and in $45 \%$ of oral squamous cell carcinoma patients $(p<0.001)$.

In conclusion, it is noteworthy that comprehensive dermatoglyphic research of hypothenar traits in twins is needed to further elucidate the intimate relationships between heritability and environment in human pathology. 


\section{Acknowledgments}

None.

\section{Conflicts of interest}

Author declares that there is no conflict of interest.

\section{References}

1. Temaj G, Škarić-Jurić T, Tomas Ž, et al. Qualitative dermatoglyphic traits in monozygotic and dizygotic twins of Albanian population in Kosovo. Homo. 2012;63(6):459-467.

2. Maslarski I. Qualitative dermatoglyphic traits in twins. Acta Morphol Anthropol. 2015;22:79-87.

3. Scheil HG, Schmidt HD, Vulpe C, et al. Dermatoglyphic studies in Romania. Anthropol Anz. 2008;66(3):273-279.

4. Karev GB. Hypothenar radial arch in man: observations on its distribution, morphology, symmetry, and inheritance. Am $J$ Phys Anthropol. 1991;84(4):479-487.

5. Karev GB. Three palmar dermatoglyphic traits and their asymmetry in Bulgarian right-, mixed- and left-handers. Anthropol Anz. 2011;68(3):291307.

6. Loesch D. Genetical studies of the palmar and sole patterns and some derrnatoǵlyphic measurements in twins. Ann Hum Genet. 1979;43(1):3753.

7. Andreenko E, Baltova S. Sexual dimorphism in dermatoglyphic traits and fluctuating asymmetry in Bulgarians from northwest Bulgaria. Homo. 2017;68(4):316-327.

8. Rosa A, Arquimbau R, Fañanás L. Quantitative and qualitative palmar dermatoglyphics in the Mediterranean population of Delta de l'Ebre (Spain). Int J Anthropol. 1998;13(2):89-96.

9. Kavgazova L, Stoev R, Mitova Z. Dermatoglyphic characteristics of a population from the central Rhodopes (South Bulgaria). Anthropol Anz. 1999;57(4):349-360.

10. Sokal R, Livshits G. Geographic variation of six dermatoglyphic traits in Eurasia. Am J Phys Anthropol. 1993;90(4):393-407.

11. Ray E. Frequency of patterns in palms. J Forens Identify. 2012;62:568587

12. Callegari-Jacques SM, Salzano FM, Pena HF. Palmar dermatoglyphic patterns in twins. Hum Hered. 1977;27:437-443.

13. Temaj G, Krajacić P, Milicić J, et al. Comparative analysis of qualitative dermatoglyphic traits of Albanian and Turkish populations living in the area of Dukagjin Valley in Kosovo. Coll Antropol. 2011;35(3):905-910.

14. Sognier MA, Kloepfer HW, Cummins H. The inheritance of the hypothenar whorl. Birth Defects. 1979;15:543-555.
15. Maslarski II, Belenska LF. Qualitative analysis of prints of palms and fingers of twins. J Global Biosci. 2015;4:2833-2841.

16. Ravindranath R, Shubha R, Nagesh HV, et al. Dermatoglyphics in rheumatoid arthritis. Indian J Med Sci. 2003;57:437-441.

17. Bosco JI, Rajangam S, Shankar J, et al. Dermatoglyphics in 46, XY females. J Indian Med Assoc. 2001;99:418-420.

18. Watanabe K, Nakamura R, Miura T. Palmar dermatoglyphics in congenital hand anomalies. J Hand Surg Am. 1994;19(6):961-967.

19. Sivkov S, Akabaliev V. Dermatoglyphics in schizophrenia: qualitative aspects. Folia Med. 1998;40:44-50.

20. Kashamat T. Clinical, cytogenetic and dermatoglyphic studies on handicapped patients. Acta Med Univ Kagoshimaensis 1987;29:129-152.

21. Jindal G, Pandey RK, Gupta S, et al. A comparative evaluation of dermatoglyphics in different classes of malocclusion. Saudi Dent J. 2015;27(2):88-92.

22. Sridevi NS, Delphine Silvia CR, Kulkarni R, et al. Palmar dermatoglyphics in carcinoma breast of Indian women. Rom J Morphol Embryol. 2010;51(3):547-550.

23. Zuk O, Hechter E, Sunyaev SR, et al. The mystery of missing heritability: Genetic interactions create phantom heritability. Proc Natl Acad Sci USA. 2012;109(4):1193-1198.

24. Milicic J, Pavicevic R, Halbauer M, et al. Analysis of qualitative dermatoglyphic traits of the digito-palmar complex in carcinomas. In: Durham NM, Fox KM, Plato CC, editors. The State of Dermatoglyphics: The Science of Finger and Palm Prints. Lewinston, ME: The Edwin Mallen Press; 2000. p. 53-72.

25. Gradiser M, Matovinovic Osvatic M, Dilber D, et al. Assessment of environmental and hereditary influence on development of pituitary tumors using dermatoglyphic traits and their potential as screening markers. Int $J$ Environ Res Public Health. 2016;13(3).

26. Till M, Larrauri S, Smith PG. Dermatoglyphics in childhood leukaemia: a guide to prognosis and aetiology? Br J Cancer. 1978;37:1063-1073.

27. Buković D, Persec Z, Buković N, et al. Qualitative dermatoglyphic traits in ovarian cancer patients: a case-control study. Coll Antropol. 1999;23(2):641-644.

28. Venkatesh E, Bagewadi A, Keluskar V, et al. Palmar dermatoglyphics in oral leukoplakia and oral squamous cell carcinoma patients. J Indian Acad Oral Med Radiol. 2008;20:94-99.

29. Lakshanika AN. A new innovative technique for analysis of palmar dermatoglyphics in oral leukoplakia patients. Res J Pharm Biol Chem Sci. 2016;7:1940-1948.

30. Vijayaraghavan A, Aswath N. Qualitative and quantitative analysis of palmar dermatoglyphics among smokeless tobacco users. Indian J Dent Res. 2015;26:483-487. 